\title{
QUAIS OS
}

\section{CONDICIONANTES PARA A \\ MELHORINSERCAO \\ DOS PEQUENOS NEGÓCIOS NO}

MUNDO DICITAL?

Carlos Eduardo Flores e

Roberto Pedreira

Há, pelo menos, duas décadas, diversos estudos e pesquisas realizados por instituições que estudam e estimulam a atividade empresarial no país têm demonstrado a relevância dos pequenos negócios para o desenvolvimento econômico brasileiro. E, mesmo em tempos de crise, como a que se vivencia atualmente, reforça-se ainda mais o papel dessas empresas de micro e pequeno porte, diante do impacto que faz estremecer os níveis de produção e produtividade, os empregos e a massa salarial.

Na fase inicial da atual crise sanitária, diversas atividades econômicas ficaram paralisadas, a sociabilidade e a mobilidade de pessoas, bens e serviços foram restringidas, contraindo agressivamente as economias do mundo todo, e no Brasil não foi diferente. Também não tem sido diferente a saída encontrada pelas empresas. O tema "transformação digital", processo de transformar o modelo de negócio pelo uso de ferramentas digitais, e pela mudança nas relações com o consumidor, tem conquistado um peso relevante, como estratégia para a sobrevivência e recuperação dessas atividades.

O que vinha acontecendo nas empresas de forma moderada há, pelo menos, 10 anos, foi acelerado com toda força por essa crise sanitária, empurrando para o mundo digital um universo de pequenos negócios que desconheciam ou pouco atuavam nesse ambiente, obrigando-os a uma brusca adaptação, para não serem atropelados e deixados para trás.
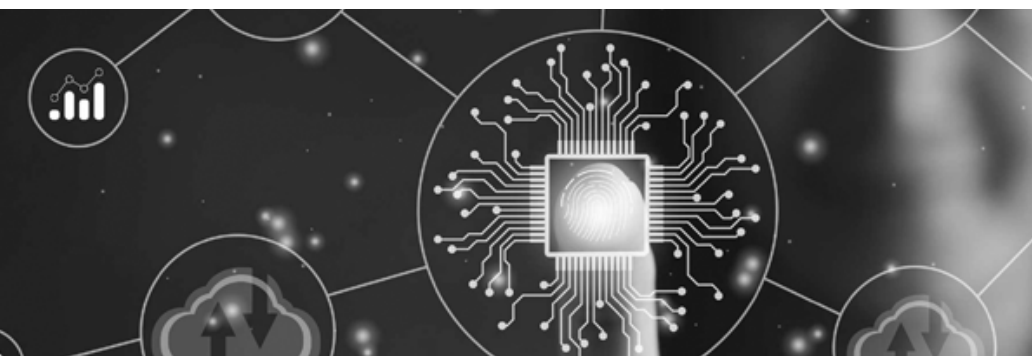

C
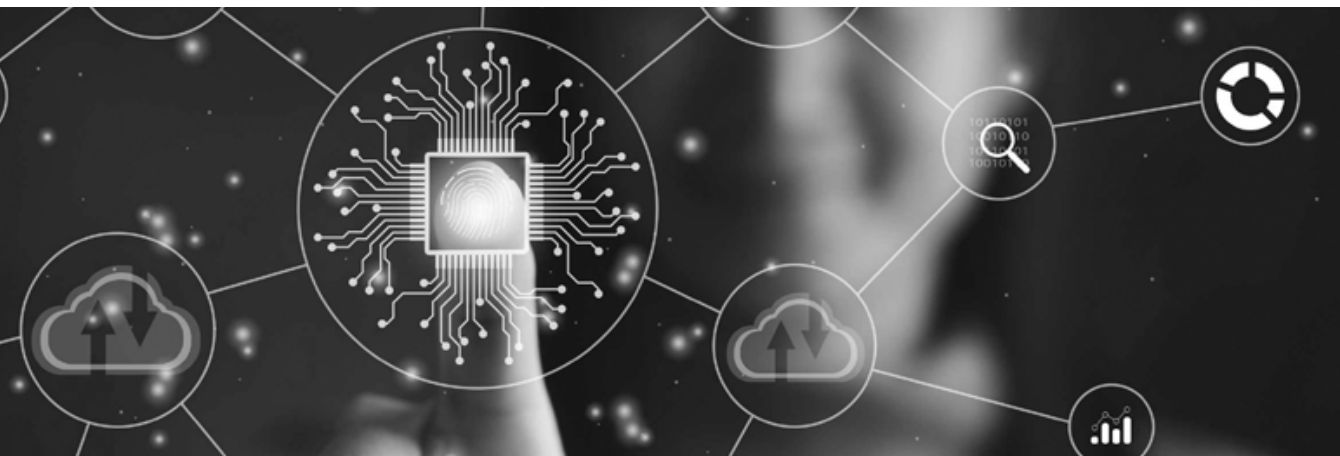
Vale salientar que o avanço tecnológico das últimas décadas modificou de forma significativa as formas convencionais de organização econômica e social. Esse progresso está associado à propagação de um conjunto de novas tecnologias, entre as quais se destacam as digitais, que colocam em evidência o processo de conectividade que percorre todas as dimensões do consumo, da cultura, da sociabilidade e da economia. A difusão da transformação digital nas empresas e a maior aplicação das tecnologias de informação e comunicação (TIC) pelo uso de equipamentos e máquinas conectados em rede têm favorecido a inovação em setores e subsetores econômicos pela sua relevância e aprendizado nos vários âmbitos da vida cotidiana.

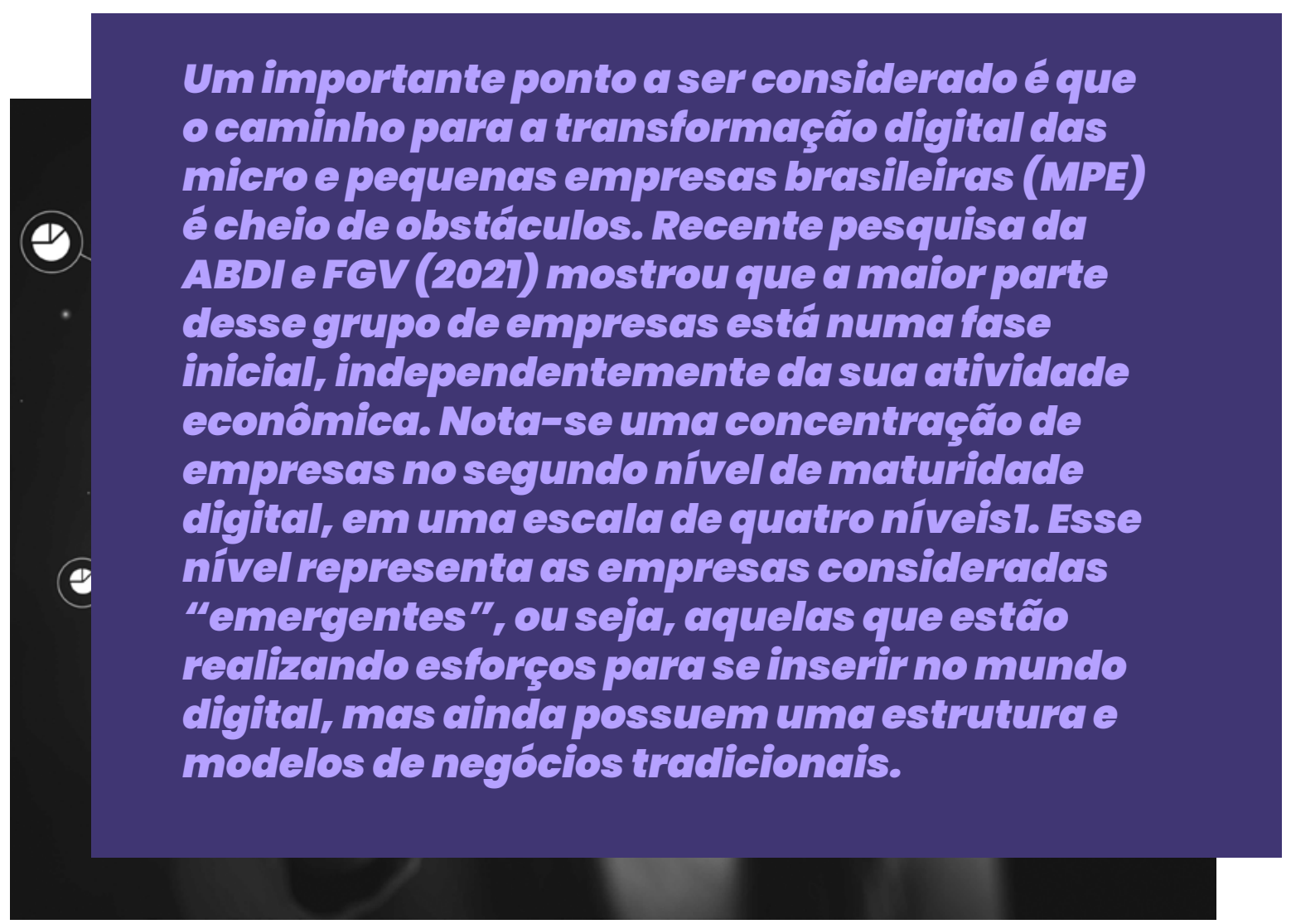

Se, de um lado, esse resultado demonstra que as práticas e estratégias de transformação digital estão pouco consolidadas entre as MPE, por outro lado são identificadas muitas oportunidades. Quando se vê, por exemplo, uma microempresa familiar de Vitória da Conquista, interior da Bahia, de uma atividade tradicional (armarinho), adotando soluções digitais de baixa complexidade que ajudaram a reaquecer e ampliar a comercialização, percebe-se que, para os pequenos negócios brasileiros, a inserção no mundo digital é inexorável. 
Se os pequenes negócios sc̃o considerclos c "força motriz" da economia brasileira e existem oportunidades para a inserção no mundo digitul, - que os têm impedido de adotar estratégias e ferramentas de transformação digitalb Quais os condicionantes para uma inserçäo mais robusta das MPE no mundo digitell?

Defende-se que o apoio do Estadoé condiģấ imprescindfrel perra ๑ use mais intensivo de ferramentas tecnológicas digitulis e de dados, por parte ders MPE brasileires.

Esse apoio passa, necessariamente, pela necessidade de promover a extensão das infraestruturas digitais e remodelar medidas legais e instrumentos, cujos desenho e implementação estão distantes de um modelo baseado em uma concertação, balizada por uma política pública ou agenda.

Isso não significa que as medidas e instrumentos adotados pelos governos em apoio às MPE ao longo dos últimos anos e, particularmente em 2020 e 2021, não tenham sido importantes. Os recentes programas de suporte ao emprego, de linhas ao crédito e de redução de impostos proporcionaram a manutenção das operações das empresas, como pagamentos de dívidas, compra de insumos, materiais e equipamentos, além da folha salarial, amortecendo os impactos negativos da crise sanitária na economia. Em suma, foram importantes, encontravam-se na agenda de governo, mas não estavam dentro de um contexto de uma estratégia conjunta, envolvendo governos, instituições públicas e privadas, e setor empresarial, com o olhar no médio e longo prazo.

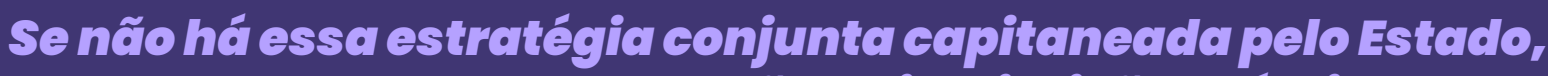

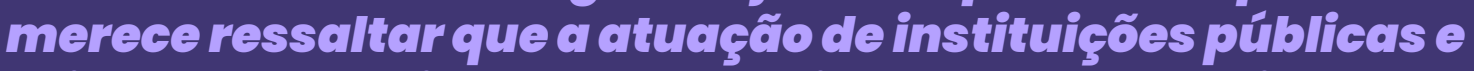
privades de epoio ao desenvolvimento empreserric/ tem sido erucial perra conseientizer, difundir e estimular práticess e estratégios de transformação digital nas MPE. Fm diverscrs

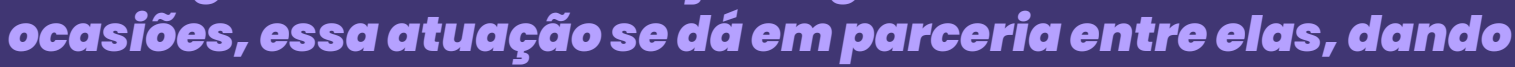
uma maior musculcrtura às inciativas postas em prátice. 


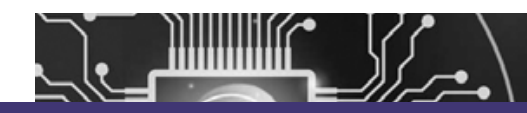

\section{No decorrer da atual erise, muitas des ações adotadas amorteceram os efeitos da pandemia e das medidas que restringiram o funcionamento das atividades consideradas nã̊ essenciais.}

Mas não é suficiente. E a pesquisa realizada pela ABDI e FGV mostra que ainda há diversos gargalos para a inserção das MPE no processo de transformação digital. A falta de recursos para investir na transformação digital e a dificuldade em compreender quais deveriam ser as prioridades de investimento são questões que atingem mais de $50 \%$ dos pequenos negócios que demonstram interesse em seguir no caminho da transformação digital.

Gráfico 1 - As principais dificuldades com a transformação digital, segundo as MPE

Falta de recursos para investir na transformaçâo digital

Dificuldade em acessar pessoas ou empresas com capacidade de ajudar a empresa

Dificuldade em compreender quais deveriam ser as prioridades de investimento

Falta de estratégia da empresa para atuar no mundo digital

Falta de tecnologias básicas na empresa que permitam usar tecnologias mais avançadas

Outros Resistência à mudança por parte dos diretores/gerentes

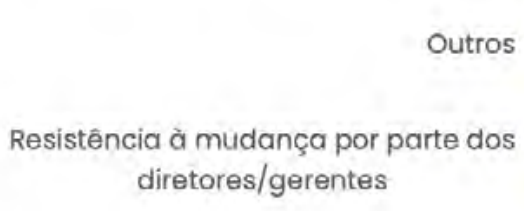

$0 \%$

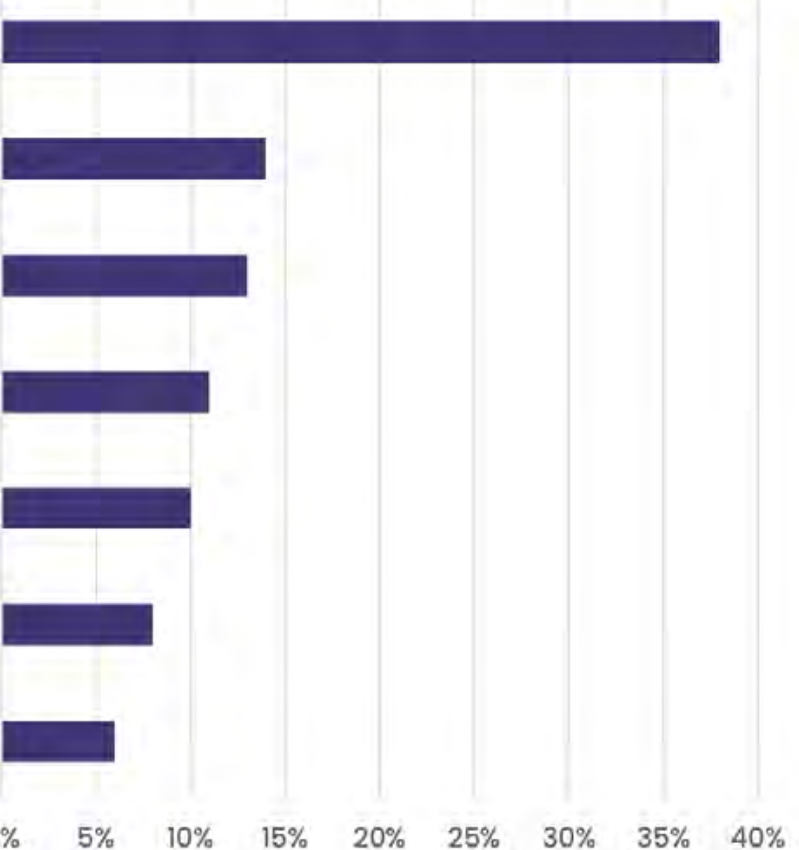


Isse demonstra que cs MPE necessitem de uma nova fase

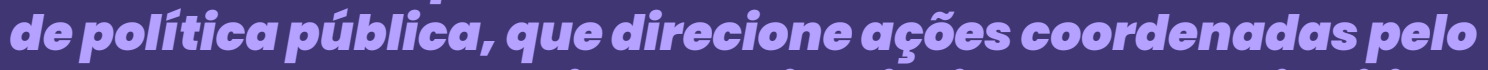

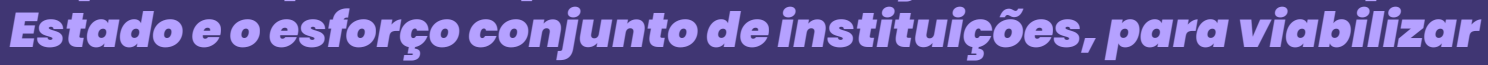

- uso mais intensive de teenologias digitais. Sem reeurses fincheeiros perra aquisição de equipermentos e soluçöes digitalis; sem apoio téenico qualifieddo que diagnostique as "dores" especfificas de edda empresa e desenvolva noves

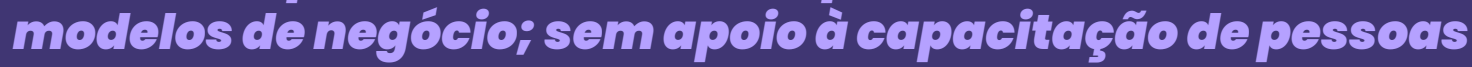
para $\odot$ use adequado dos dados e das ferramentas digitais, - ecminho dos pequenos negócios para a transformaģčo digital fieerá, pratieamente, bloqueddo.

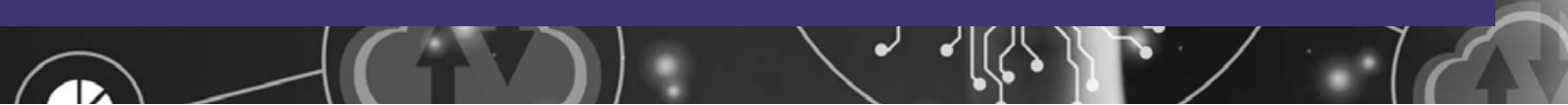

A "mão invisível" do Estado não pode largar as MPE sozinhas. É necessário que lhe sejam apresentados os caminhos e, de mãos unidas, transpor os obstáculos, levando-as à inserção plena e robusta no mundo digital.

A tecnologia é uma categoria que se relaciona com as normas sociais e elementos da dimensão institucional, contribuindo na formatação do mercado de trabalho, nas práticas organizacionais, das políticas públicas e no comportamento social. Nesse contexto, o processo de transformação digital impõe-se como uma forte influenciadora dos processos de desenvolvimento econômico, social e político. Por isso, ressalta-se o papel do Estado como importante agente promotor e facilitador de mudanças institucionais e tecnológicas, ao coordenar, promover e fomentar áreas estratégicas, alocando recursos públicos adequados aos agentes portadores de inovações e sinalizando as direções e a intensidade da atuação e dos investimentos em ciência e desenvolvimento tecnológico das instituições públicas e privadas que orbitam no ecossistema de inovação.

Nesse ecossistema nacional, há muitas instituições que aportam recursos técnicos e financeiros para apoiar o desenvolvimento tecnológico empresarial. Algumas delas estão voltadas especificamente para os pequenos negócios. E um ponto positivo é que todas elas têm direcionado esforços para difundir a transformação digital, influenciadas (mas, sem coordenação) pela Estratégia Brasileira para a Transformação Digital ${ }^{2}$, lançada em 2018, pelo Ministério da Ciência Tecnologia, Inovações e Comunicações.

Nesse cenário em prol da transformação digital, a Agência Brasileira de Desenvolvimento Industrial (ABDI), a partir de 2019, estabeleceu um reposicionamento estratégico, tendo como foco de atuação a promoção do aumento da maturidade digital dos setores econômicos brasileiros, com o espírito de cooperação com diferentes atores. 
Com o objetivo de criar um ambiente propício para o aumento da maturidade digital, removendo as barreiras externas que dificultam a adoção de tecnologias digitais pelas empresas, a ABDI, que está vinculada ao Ministério da Economia (ME), vem desenvolvendo iniciativas voltadas às MPE para ampliar a inclusão digital, estimular a adoção de novos modelos de negócios e impulsionar o uso e a aplicação de tecnologias digitais, entre as quais se destacam o Programa Digital.br, que seleciona e financia projetos, por meio de uma chamada pública, executados por redes e ecossistemas de inovação, os quais receberam apoio financeiro e técnico da ABDI, e o projeto Jornada Digital, que oferece um passo a passo com soluções que podem ser adotadas pelas MPE, a depender de suas especificidades e expectativas, e a partir da identificação do estágio em que a empresa se encontra.

Esses programas da ABDI se caracterizam como importantes exemplos de iniciativas de apoio à transformação digital de pequenos negócios. A primeira edição do Digital.br, iniciada em junho de 2020, abrangeu projetos voltados para micro, pequenas e médias empresas situadas exclusivamente na Região Nordeste, sendo que 17 (dezessete) projetos receberam capacitação e mentoria para aperfeiçoamento metodológico, por meio de ferramentas de design thinking, design etnográfico e métodos ágeis; isso significou a qualificação de mais de 80 formuladores, representantes das instituições públicas e privadas que compunham as redes de inovação responsáveis pelos projetos.

Após essa fase, selecionou-se os 8 (oito) mais bem avaliados, que receberam apoio financeiro, por meio de uma premiação, para a implementação do projeto piloto. Cerca de 300 empresas foram beneficiadas nessa fase, registrando-se um aumento médio de maturidade digital de $20 \%$ e aumento médio de produtividade de, aproximadamente, 30\%. E, na próxima etapa, de implementação dos planos de escala, a expectativa é de beneficiar mais 950 empresas, com soluções digitais customizadas às necessidades de cada uma delas.

Paralelo à continuidade da primeira edição, a ABDI já se prepara para o lançamento do segundo edital, em outubro de 2021, dessa vez contemplando redes e ecossistemas de inovação das regiões Norte, Nordeste e Centro Oeste.

Outra iniciativa que converge com a ideia de se estabelecer um esforço conjunto de instituições para a disseminação da transformação digital é o programa direcionado para a Feira de Sulanca, em Caruaru, Pernambuco, que se alicerça numa cooperação técnica firmada entre a ABDI, o Governo Municipal de Caruaru e o SEBRAE, voltado para 100 (cem) microempreendedores individuais (MEI) e empreendedores informais, e se constitui no diagnóstico do grau de maturidade digital desses empreendedores e na elaboração de um plano de aceleração de transformação digital. 
Nesse contexto, a ABDI, ao fomentar programas de transformação digital para as micro e pequenas empresas, em determinados contextos, não somente aprimora o aparato produtivo e comercial dessas empresas, como também estimula a adoção de tecnologia que, ao interagir com o ambiente socioeconômico e político, permite o desenvolvimento de aglomerações produtivas dinâmicas, com consequente melhoria dos níveis de produtividade e da renda nacional, por intermédio do aumento das taxas de lucratividade e da massa salarial da população ocupada.

\section{Garlos Eduardo Flores de Araúje}

Economista e mestre em Geografia pelo IGC-UFMG, possui MBA em Transformação Digital e Futuro dos Negócios pela PUC/RS, Desenvolvimento Produtivo pela ENAP e Finanças pelo IBMEC.

Especialista em análise econômica na Agência Brasileira de

Desenvolvimento Industrial- ABDI, Carlos Flores é ex-assessor especial do ministro do Ministério de Desenvolvimento, Indústria e Comércio ExteriorMDIC, ex-assessor especial da presidência da Companhia Energética de Minas Gerais- Cemig e ex-gerente de desenvolvimento econômico da Prefeitura Municipal de Belo Horizonte.
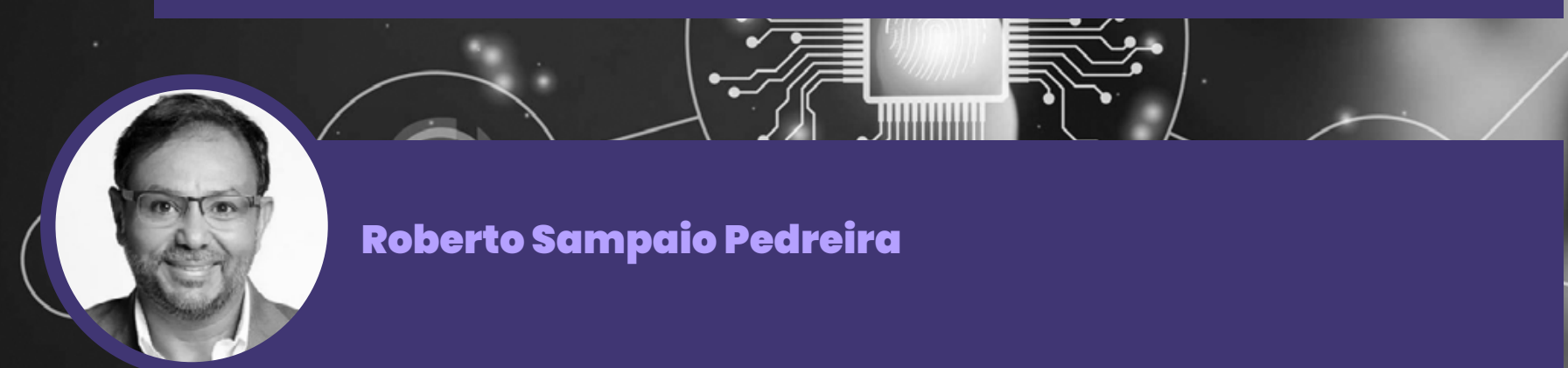

Economista e Doutor em Ciências Sociais, pelo CEPPAC/UnB, possui um MBA em Transformação Digital e Futuro dos Negócios, pela PUC/RS. É Analista de Produtividade e Inovação, na Agência Brasileira de Desenvolvimento Industrial - ABDI. 


\section{NOTAS}

1 Segundo o Mapa de Digitalização das Micro e Pequenas Empresas Brasileiras, o primeiro nível é o Analógico (18\% das MPE); o segundo, Emergente (48\%); o terceiro é o Intermediário (30\%), e o quarto nível é o do líder digital (3\%). ABDI e FGV. Mapa da Digitalização das Micro e Pequenas Empresas Brasileiras. Brasília e Rio de Janeiro. 2021.

2 MCTIC. Estratégia Brasileira para a Transformação Digital - E-Digital. Brasília, 2018. https://www.gov.br/mcti/pt-br/centrais-de-conteudo/comunicados-mcti/ estrategia-digital-brasileira/estrategiadigital.pdf

\section{REFERÊNCIAS BIBLIOGRÁFICAS}

ARBACHE, Jorge. A recuperação passa pelas PMEs. Jornal Valor Econômico, 09 de setembro de 2021; p. A-21.

KALIL, Renan Bernadi. Tecnologia, instituições, ideologia e o futuro do trabalho. In: A regulação do trabalho via plataformas digitais. p. 35-66, São Paulo: Ed. Blucher, 2020. 